\title{
Incidence of Colibacillosis in Poultry in Gonda District in North Eastern Plain Zone of Uttar Pradesh
}

\author{
Abhishek Mishra ${ }^{1}$, Debasish Niyogi ${ }^{1}$, Rakesh Kumar Gupta ${ }^{1 *}$, Krishna Kant Tripathi ${ }^{1}$ and Satya Vrat Singh $^{2}$ \\ ${ }^{1}$ Department of Veterinary Pathology, C.V.Sc E A.H, ANDUAT, Kumarganj, Ayodhya, Uttar Pradesh, INDIA \\ ${ }^{2}$ Department of Veterinary Medicine, C.V.Sc E A.H, ANDUAT, Kumarganj, Ayodhya, Uttar Pradesh, INDIA
}

"Corresponding author: RK Gupta; E-mail: rakeshguptaa96@gmail.com

Received: 08 May, $2020 \quad$ Revised: 02 Sept., $2020 \quad$ Accepted: 10 Sept., 2020

\begin{abstract}
The present study was undertaken with the objective to study the incidence of E. coli infection in broiler chicken in Gonda district of Uttar Pradesh. For this study a total number of 483 naturally dead broiler chickens from 8 different private farms of Gonda district were collected during June 2018 - May 2019. The overall incidence of colibacillosis was 38.09\% (184 samples were positive out of 483 samples). The gross change of liver was found as enlarged, congested and covered with thick yellow/white serofibrinous covering. Heart was also covered with thick yellow/white serofibrinous covering. Among tested 483 samples from 8 private farms from Gonda district, 184 (38.09\%) were found to be suggestive of $E$. coli giving typical large (2-3 mm) lactose fermenting pink coloured colonies on Mac Conkey's agar plate. They again produced characteristic 'metallic sheen' on EMB agar. On Gram staining during morphological study, they produced pink coloured, rod shaped ones (that is gram negative) with characteristic arrangement. All these isolates (from district Gonda) showed typical biochemical reaction which were positive to Indole test, M.R. test, T.S.I. agar test, nitrate reduction test and negative to VP test and $\mathrm{H}_{2} \mathrm{~S}$ production test. Among $184 \mathrm{E}$. coli isolates $98.36 \%$ were negative to citrate utilization test and $97.82 \%$ to urease activity test. Out of 184 isolates of E. coli 179 were motile. They all fermented D-glucose, lactose, manitol. Among 184 isolates of E. coli, 154 (83.69\%) isolates, $158(85.86 \%)$ isolates and $144(78.26 \%)$ isolates had shown fermentation of sucrose, dulcitol and salicin respectively.
\end{abstract}

\section{HIGHLIGHTS}

(0) The overall incidence of colibacillosis was $38.09 \%$.

0 The serofibrinous covering on liver and heart is a pathognomic lesion of colibacillosis.

(- E. coli produce characteristic 'metallic sheen' on EMB agar.

Keywords: Colibacillosis, Gonda, E. coli, incidence

Poultry farming in reality is an important tool for providing self-employment, supplementary income, and eradication of rural poverty and to combat malnutrition by providing cheap source of animal protein as egg and meat with high biological value. It plays a vital role in the supplementation of food protein of high value. The adoption of genetical hybridization geared up the country. Broiler raising in an important part of poultry industry in India and poultry meat is becoming popular day by day. The poultry industries are most vulnerable to attack by infections that increased mortality of poultry chickens. Avian colibacillosis is one of the most common infectious diseases seen in poultry of all age group and usually found in young chick of up-to three weeks of age (Kabir, 2010; Singh et al., 2018).

Avian colibacillosis refers to any localized or systemic infection caused entirely or partly by Avian Pathogenic Escherichia coli (APEC), including colisepticaemia,

How to cite this article: Mishra, A., Niyogi, D., Gupta, R.K., Tripathi, K.K. and Singh, S.V. (2020). Incidence of colibacillosis in poultry in Gonda district in north eastern plain zone of Uttar Pradesh. J. Anim. Res., 10(5): 837-841.

Source of Support: None; Conflict of Interest: None 
coligranuloma (Hjarre's disease), air sac disease, swollen head syndrome, venereal colibacillosis and coliform cellulitis, peritonitis, salphingitis, orchitis, osteomyelitis/ synovitis, panopthalmitis, omphalitis/yolk sac infection and enteritis. Transmission occurs generally by shell penetration, transovarian infection and horizontal transmission through contaminated feed, water infected litter, dust particles, instruments, equipments of the farms and also by mechanical carrier.

E. coli, a gram negative, rod-shaped, non-capsulated, motile, and generally non-haemolytic and lactose fermenting organism was first isolated from faeces of a new born in 1885 by Theobald Escherich. E. coli is one of such virulent pathogens which causes havoc economic loss to poultry industry (Hofstad, 1975). E. coli is a common inhabitant of the intestinal tract at a concentration of $10^{6} /$ gm of faeces or less (Gross, 1991).

Colibacillosis causes embryo mortality and omphalitis in chicks. Lesions observed are mainly polyserositis with deposition of fibrin in the air sacs, pericardium and liver (Yousseff et al., 2008; Kabir, 2010; Singh et al., 2018). Colibacillosis in broiler birds can be diagnosed by clinical symptoms, post mortem lesions, and isolation of organism from the site of lesions. Confirmatory diagnosis can be made by isolation and identification of $E$. coli from heart blood of sick birds especially by EMB media and also by bio-chemical tests.

In India, much work has been done on isolation of $E$. coli from broiler chicken but very limited work has been conducted on the pathological changes due to E. coli infection in broiler chicken in North Eastern Plain Zone of Uttar Pradesh. Though some work was conducted on the incidence of spontaneous $E$. coli infection in broiler chickens in Faizabad and Sultanpur districts of Eastern Uttar Pradesh but no work was done on the incidence of E. coli infection in Gonda district in North Eastern Plain Zone of Uttar Pradesh. Keeping in view the immense importance of this disease in broiler industry, the present study was undertaken with the objective to study the incidence of $E$. coli infection in broiler chicken in Gonda district of Uttar Pradesh.

\section{MATERIAL AND METHODS}

The present study was undertaken to establish the incidence of $E$. coli infection in broiler chickens reared in Gonda district of North Eastern Plain Zone of Uttar Pradesh. Two broiler farms from each Tehsil of the district were selected on the basis of stratified random sampling. A total number of 483 naturally dead broiler chickens from 8 private farms from Gonda district of North Eastern Plain Zone of Uttar Pradesh were collected within 6 hours of death throughout the year (June 2018 - May 2019). The birds were of different age group and of both sexes. After post mortem examination, all the gross lesions were recorded. For bacteriological study, materials from grossly suspected birds with $E$. coli infection were collected. The pieces of liver, lungs, heart, intestine, and spleen were aseptically collected from the dead birds showing gross pathological lesions of suspected E. coli infection i.e. yellow/white sero-fibrinous covering over liver, heart, and peritoneum, congestion of lung and heart, intestinal haemorrhages and necrotic foci on liver. They were kept in sterile vials separately and brought to the Veterinary Microbiology Laboratory under ice coverage for further study. The method described by Cruickshank et al. (1975) was used for the isolation of $E$. coli and the isolates were identified on the basis of morphology, motility, and colony characteristics and bio-chemicals properties as per the method of Edwards and Ewing (1972).

\section{RESULTS AND DISCUSSION}

The samples (483 dead birds) were collected from Gonda district of North Eastern Plain Zone of Uttar Pradesh, suspected to be suffering from colibacillosis. The diagnosis was confirmed on the basis of pathognomic lesions, and isolation and identification of the causative organism. The overall incidence of colibacillosis was $38.09 \%$ (184 samples were positive out of 483 samples) which was similar to the reports of Phukan (1988) who reported $50.84 \%$ overall incidence of $E$. coli infection and Singh et al. (2018) who observed $53.37 \%$ positive cases of colibacillosis. The incidence in the present study was also similar with the findings of Chandra et al. (2008) and Ashraf et al. (2015) in the broiler chicken. The detail incidence of farms is shown in table 1.

The gross changes of liver were found as enlarged, congested and covered with thick yellow/white serofibrinous covering. The serofibrinous membrane covered the liver either partially or completely that differs with degree and severity of infection (Fig. 1 and 2). 
Table 1: Colibacillosis diagnosed in eight farms under study along with morbidity, mortality patterns and age of the affection

\begin{tabular}{|c|c|c|c|c|c|c|c|}
\hline 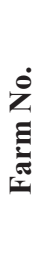 & 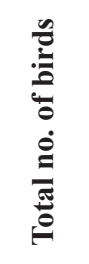 & 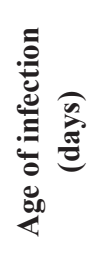 & 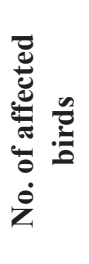 & 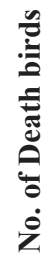 & 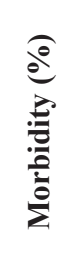 & 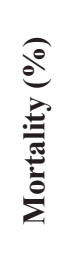 & 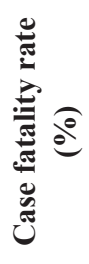 \\
\hline 1 & 4000 & $12-18$ & 162 & 98 & 4.05 & 2.45 & 60.49 \\
\hline 2 & 3000 & $7-11$ & 145 & 76 & 4.83 & 2.53 & 52.41 \\
\hline 3 & 2000 & $21-27$ & 109 & 38 & 5.45 & 1.90 & 34.86 \\
\hline 4 & 2500 & $15-22$ & 81 & 36 & 3.24 & 1.44 & 44.44 \\
\hline 5 & 3000 & $19-25$ & 126 & 89 & 4.2 & 2.96 & 70.63 \\
\hline 6 & 1500 & $10-16$ & 68 & 41 & 4.53 & 2.73 & 60.29 \\
\hline 7 & 5000 & $17-23$ & 289 & 83 & 5.78 & 1.64 & 28.71 \\
\hline 8 & 1200 & $18-25$ & 42 & 23 & 3.5 & 1.91 & 54.76 \\
\hline
\end{tabular}

In intestine hemorrhages, congestion and edematous swelling were noted. Heart was also covered with thick yellow/white serofibrinous covering (Fig. 1 and 2). In severe E. coli infection, the serofibrinous membrane covered all the visceral organs continuously (Fig. 1 and 2). The gross lesions observed in the present study corroborated with the findings of Tonu et al. (2011), Daud et al. (2014), Parwez et al. (2015) and Singh et al. (2018).

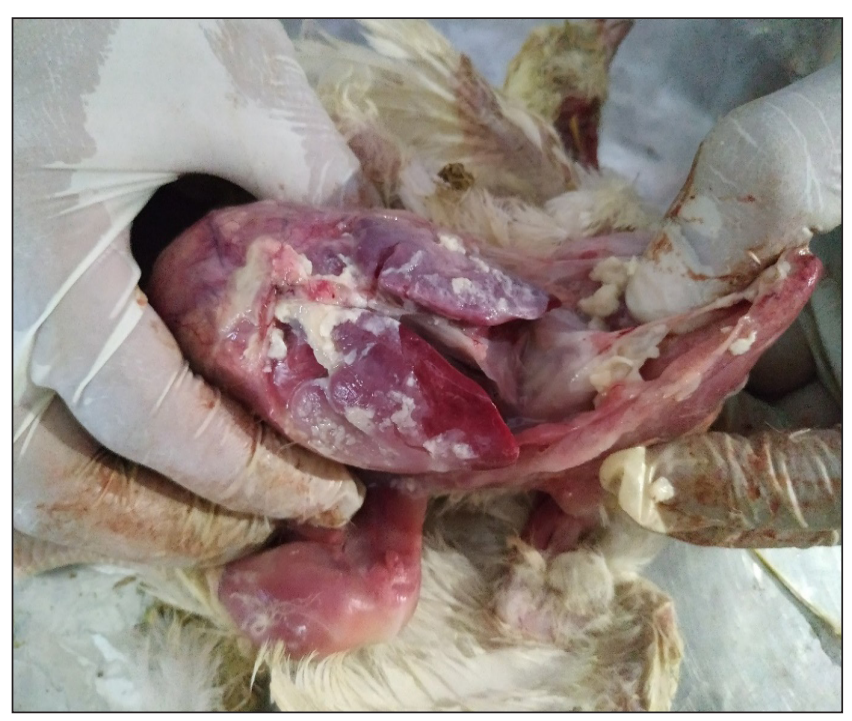

Fig. 1: Colibacillosis affected bird showing thick white serofibrinous covering over visceral organs (pathognomic lesion)

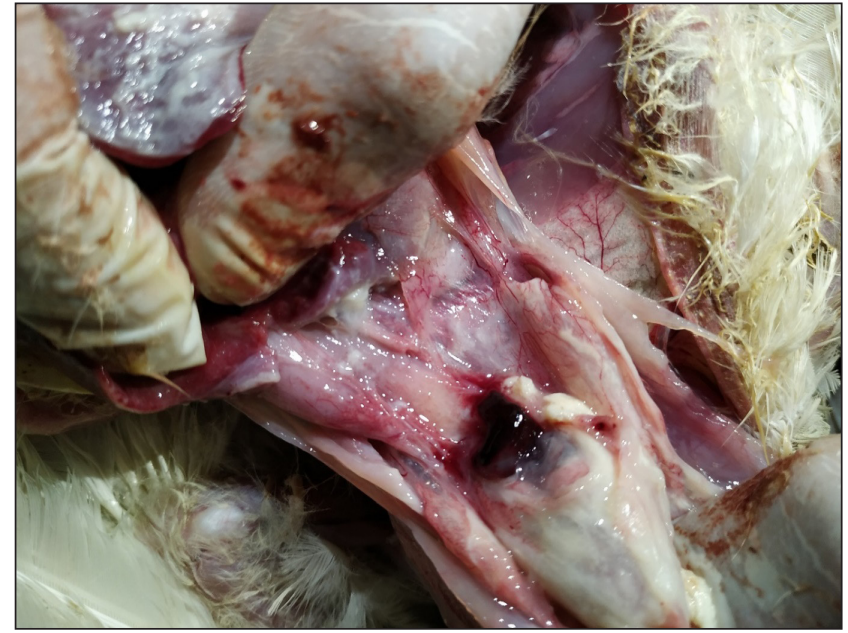

Fig. 2: Colibacillosis affected bird showing completely enclosed heart by sero-fibrinous covering (pathognomic lesion)

Among tested 483 samples from 8 private farms from Gonda district, 184 (38.09\%) were found to be suggestive of $E$. coli giving typical large (2-3 mm) lactose fermenting pink coloured colonies on Mac Conkey's agar plate (Fig. 3). They again produced characteristic 'metallic sheen' on EMB agar (Fig. 4). On Gram staining during morphological study, they produced pink coloured, rod shaped ones (that is gram negative) with characteristic arrangement (Fig. 5). These finding were in accordance with Edward and Ewing (1972).

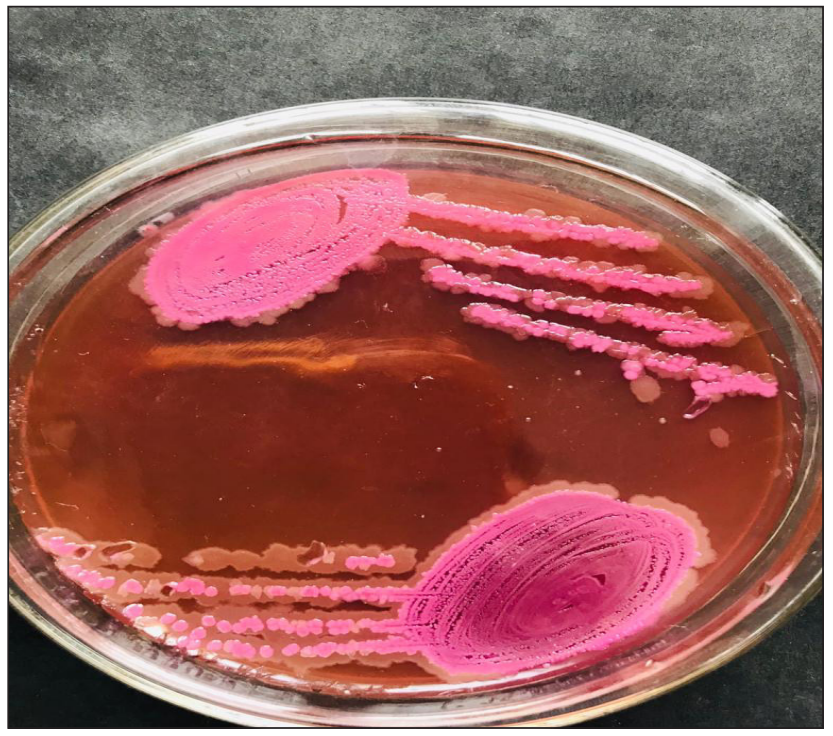

Fig. 3: Showing characteristic pink colour colonies given by $E$. coli strain, on Mac Conkey's agar plate 


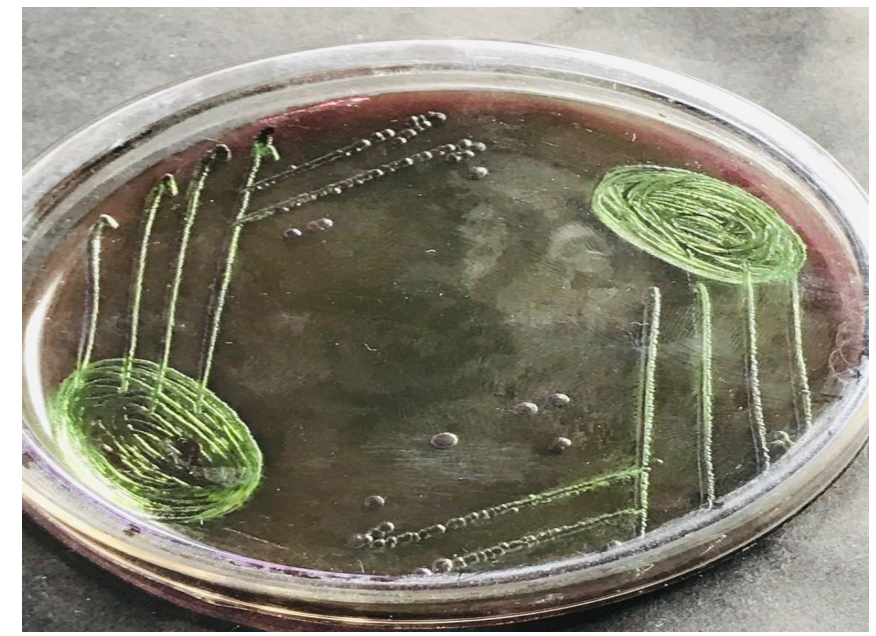

Fig. 4: Showing characteristic metallic sheen given by E. coli strain, on Eosin Methylene Blue agar plate

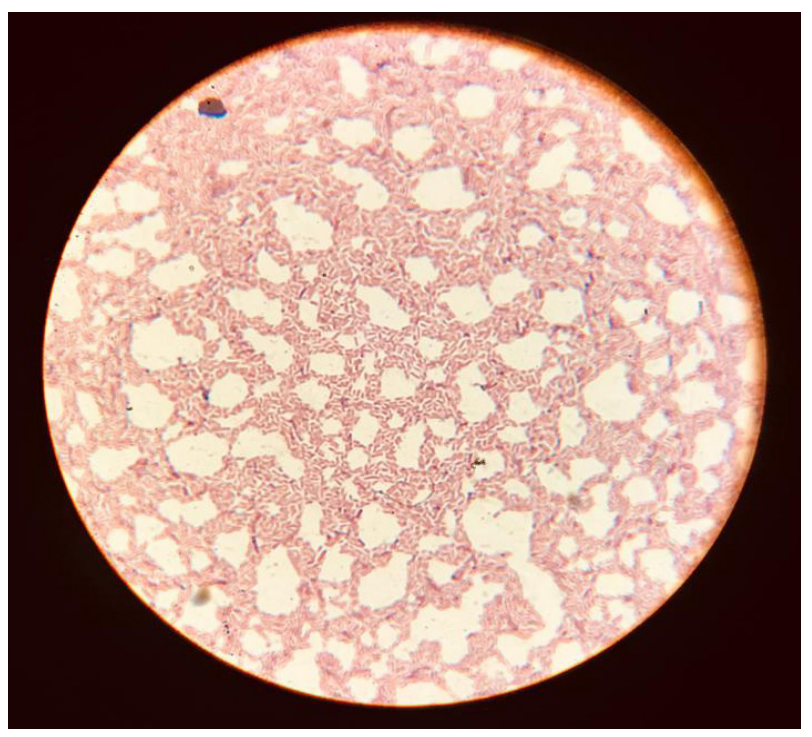

Fig. 5: Showing Gram staining of E. coli producing rod shaped, pink coloured colonies (1500X)

The presumptive E. coli isolates had shown typical biochemical reactions. This confirmed these isolates. All these isolates (from district Gonda) showed typical biochemical reaction which were positive to Indole test, M.R. test, T.S.I. agar test, nitrate reduction test and negative to VP test and $\mathrm{H}_{2} \mathrm{~S}$ production test. Among 184 E. coli isolates $98.36 \%$ were negative to citrate utilization test and $97.82 \%$ to urease activity test. Out of 184 isolates of $E$. coli 179 were motile. They all fermented D-glucose, lactose, manitol. Among 184 isolates of E. coli, 154
$(83.69 \%)$ isolates, $158(85.86 \%)$ isolates and $144(78.26 \%)$ isolates had shown fermentation of sucrose, dulcitol and salicin respectively. Only two isolate fermented adonitol. The result of bio-chemical reaction of $E$. coli are presented in Table. 2.

Table 2: Result of bio-chemical reactions shown by E. coli isolates of Gonda district

\begin{tabular}{|c|c|c|c|c|}
\hline \multirow{2}{*}{$\begin{array}{l}\text { Bio-chemical } \\
\text { reaction }\end{array}$} & \multicolumn{2}{|c|}{ Positive } & \multicolumn{2}{|c|}{ Negative } \\
\hline & Number & Percentage & Number & Percentage \\
\hline $\begin{array}{l}\text { Indole test at } \\
37^{\circ} \mathrm{C}\end{array}$ & 184 & 100 & - & - \\
\hline Methyl Red & 184 & 100 & & \\
\hline $\begin{array}{l}\text { Vogas } \\
\text { Proskauer }\end{array}$ & - & - & 184 & 100 \\
\hline $\begin{array}{l}\text { Citrate } \\
\text { utilization }\end{array}$ & 3 & 1.64 & 181 & 98.36 \\
\hline Urease activity & 4 & 2.18 & 180 & 97.82 \\
\hline T.S.I. Test & 184 & 100 & - & - \\
\hline $\mathrm{H}_{2} \mathrm{~S}$ Production & - & - & 184 & 100 \\
\hline $\begin{array}{l}\text { Nitrate } \\
\text { Reduction }\end{array}$ & 184 & 100 & - & - \\
\hline Motility & 179 & 97.29 & 5 & 2.71 \\
\hline D-glucose & 184 & 100 & - & - \\
\hline Lactose & 184 & 100 & - & - \\
\hline Sucrose & 154 & 83.69 & 30 & 16.31 \\
\hline Mannitol & 184 & 100 & - & - \\
\hline Dulcitol & 158 & 85.86 & 26 & 14.14 \\
\hline Adonitol & 2 & 1.08 & 182 & 98.92 \\
\hline Salicin & 144 & 78.26 & 40 & 21.74 \\
\hline
\end{tabular}

\section{CONCLUSION}

The present investigation showed that colibacillosis is a major concern in Gonda district in North Eastern Plain Zone of Uttar Pradesh. To sustain the loss and achieve successful broiler production, it needs investigation about the incidence and pathology of the poultry (broiler) diseases. Such information is also required to take necessary actions for the prevention and control of diseases caused by bacterial pathogens. A thorough knowledge about the epidemiology, pathogenesis and pathology of a particular disease in a prerequisite for proper diagnosis of the malady, as well as for the prevention and control of the disease. 


\section{REFERENCES}

Ashraf, A., Tawab, A.E., Samir, A., Abd El Aal., Ebstisam, M.M. and Doaa, A. El. Morsey. 2015. Prevalence of E. coli in Broiler chickens in winter and summer seasons by application of PCR with its antibiogram pattern. Benha Vet. Med. J., 29(2): 119-128.

Chandra B., Niyogi D., Ghosh C.K., Shukla V.K., Joshi R.K., Jana S. and Mukhopadhayay S.K. 2008. Incidence and pathomorphology of spontaneous Escherichia coli infection in broiler birds in two districts of West Bengal. J. Interacad., 12(4): 521-524.

Cruickshank, R., Dugid, J.P., Marmion, B.P. and Swain, R.H. 1975. Medical Microbiology. 12 ${ }^{\text {th }}$ edn. Vil. II. Churchill Livingstone, Edinburgh, London and New York.

Daud, N.H.A., Hatin, N.N., Paan, F.H., Kyaw, T., Khaing, A. T., Abba, Y. and Abdullah, F.F.J. 2014. An outbreak of colibacillosis in a broiler farm. J. of Ani. and Vet. Adv. 13(8): 545-548.

Edwards, P.R. and Ewing, W.H. 1972. Identification of Enterobacteriaceae. $3^{\text {rd }}$ edn. Burgess Publishing Company, Minneapolis, Minnesota. 55: 415.

Gross, W.B. 1991. Colibacillosis in: diseases of Poultry, Edt. By Calnek, B.W. (9 $9^{\text {th }}$ Edn.) Ames, Lowa State university press, 270-278.

Hofstad, M.S. 1975. Diseases of poultry. $6^{\text {th }}$ Edn. OXFORD and IBH Pub. Co., Kolkata.
Kabir, S.M.L. 2010. Avain Colibacillosis and Salmonellosis: A closer look at epidemiology, pathogenesis, diagnosis, control and public health concerns. Inter. J. Env. Res. Pub. Health, 7: $89-114$.

Parwez, S., Prakesh, A., Nimanapalli, R., Kumar, P.R., Kumar, M. and Rahman, S. 2015. A case report of colibacillosis in a broiler bird. World. J. Phar. Res., 4(1): 854-856.

Phukan, A. 1988. Studies on the etiology and treatment of colibacillosis in poultry. M. V. Sc. Thesis of Assam Agriculture University, Guwahati.

Singh, G.K., D. Niyogi, D., Tripathi, K.K., Joshi, R.K., Singh, S.V. and Choudhary, P.K. 2018. Incidence of spontaneous $E$. coli Infection in Broiler Chickens in Faizabad and Sultanpur Districts of Uttar Pradesh. Int. J. Curr. Microbiol. App. Sci., 7: $5175-5181$

Tonu, N. S., Sufian, M. A., Sarkar, S., Kamal, M.M., Rahman, M.H. and Hossain, M.M. 2011. Pathological study on colibacillosis in chickens and detection of Escherichia coli by PCR. Bang. J. Vet. Med., 9 (1): 17-25.

Yousseff, F.M, Mona, A.A and Mansour, D.H (2008). Clinical, pathological and bacteriological investigations on airsacculitis in chickens in Ismaila province (Eygypt). J. Agr. Vet. Sci., 1(2): 71-79. 
